\title{
Parietal Cheiro-oral Syndrome
}

\author{
Mika Takayanagi, Tomohiko Shiina, Keisuke Suzuki and Koichi Hirata
}

Key words: parietal stroke, MRI, cheiro-oral syndrome

(Intern Med 59: 1115, 2020)

(DOI: 10.2169/internalmedicine.3964-19)

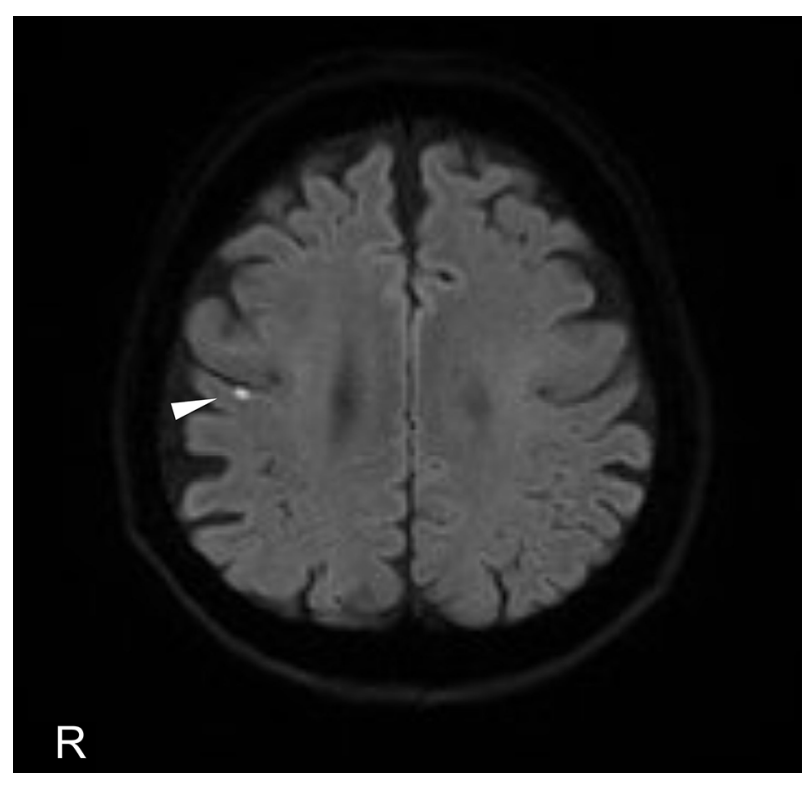

Picture.

A 72-year-old woman presented with the sudden onset of an abnormal sensation in the left perioral region and left fingers in the morning. Her blood pressure was $154 / 92 \mathrm{mmHg}$, and her pulse rate was $88 / \mathrm{min}$ with a regular rhythm. Neurological findings showed hypesthesia in the left perioral region and left fingers but were otherwise unremarkable. An electrocardiogram showed sinus rhythm. Diffusion-weighted imaging showed a high-intensity lesion in the right postcentral gyrus (Picture, arrowhead). No additional new lesions, including in the brainstem or thalamus, were found. The patient's sensory impairment improved over several days after anti-platelet and anti-coagulant therapy. Cheirooral syndrome, a pure sensory stroke involving the ipsilateral perioral region and fingers, is usually attributed to thalamic infarction but can occur in cases of parietal stroke $(1,2)$. The parietal lesion inducing cheiro-oral syndrome was much smaller in the present patient than those described in previous reports $(1,2)$, which has an important implication in our understanding of the clinico-radiological correlation of the sensory topography.

The authors state that they have no Conflict of Interest (COI).

\section{References}

1. Mrabet A, Gouider R, Bouteraa M, Haddad A. Cheiro-oral syndrome and parietal stroke. Cerebrovasc Dis 3: 183-184, 1993.

2. Yasuda Y, Watanabe T, Ogura A. Parietal cheiro-oral syndrome. Intern Med 39: 1105-1107, 2000.

The Internal Medicine is an Open Access journal distributed under the Creative Commons Attribution-NonCommercial-NoDerivatives 4.0 International License. To view the details of this license, please visit (https://creativecommons.org/licenses/ by-nc-nd/4.0/).

Department of Neurology, Dokkyo Medical University, Japan

Received: September 25, 2019; Accepted: November 28, 2019; Advance Publication by J-STAGE: January 9, 2020

Correspondence to Dr. Keisuke Suzuki, keisuke@dokkyomed.ac.jp

(C) 2020 The Japanese Society of Internal Medicine. Intern Med 59: 1115, 2020 